\title{
In the aftermath of a suicide: Any lessons from the sorrow?
}

The untimely and tragic loss of Prof. Bongani Mayosi, by his own hand, has shocked local readers of this journal, as well as colleagues around the world. As his obituary in this issue indicates, Prof. Mayosi was a truly exceptional man, who had contributed so much already and who still had so much more to give. The loss is enormous - firstly to his family, and then also to society more broadly in South Africa, Africa and globally. In the aftermath of such a loss many will feel great sorrow, amid a range of other emotions. Many questions arise as we struggle to understand the causes and ask what more we could have done.

Health professionals are, of course, well experienced in serving their communities on matters not only of life, but also of death. Still, the death of a patient or colleague may be particularly painful - when the death has come too soon, when the illness has brought much suffering, or when our efforts have contributed to the outcome. Loss to suicide is particularly sore; in our common humanity, we struggle to make sense of the decision to end a valuable life, we are plagued by questions of how this could have been prevented, and we share in the burden of the loss with family and friends.

Depression frequently underlies suicide, and doctors are well trained in the medical model. Depression, we repeat like a mantra, is a biopsychosocial health condition, a disturbance of the brain, requiring early diagnosis and treatment. There is much to be said for the value of this scientific model; it helps to destigmatise the symptoms of depression, it provides impetus for research on neurobiology and psychobiology, and it provides the foundation for a public health approach that emphasises the burden of disease, the importance of evidence-based treatments, and the cost-effectiveness of interventions.

However, the loss of a patient, or a colleague, to depression and suicide also raises broader questions. Albert Camus, a Nobelist who was born in Africa, argued that there is only one important question in philosophy: deciding on whether or not life is worth living. Hamlet's 'To be or not to be' soliloquy emphasises the 'slings and arrows of outrageous fortune'; as health professionals we are only too aware of these. Medicine may well be a vocation, but how do we find the fortitude, energy and optimism that are necessary to heal and encourage others, when life brings so much stress and suffering?

And as health professionals in South Africa, we are also only too aware of the politics of health, of the social determinants of illness, of the multiple societal injustices that intersect with death and dying. When a patient dies prematurely, we immediately ask what societal systems and processes have contributed to this outcome. When a colleague dies prematurely, we question our medical institutions and their role. When a medical leader dies prematurely, it raises questions about our expectations of our leaders, and about how we express these expectations.

Psychiatrists are used to asking the question 'How does this patient make you feel?' Experiencing intense emotion as part of the clinician-patient relationship is not merely a side-effect of being a health professional - rather, using that experience to understand the patient better and to think about better interventions is an important part of being a good clinician. In the aftermath of a suicide, we must not only grieve for the loss, but as responsible health professionals we must reflect rigorously on the underlying causes, the relevant responsibilities, and the optimal ways to prevent future occurrences.

From a biomedical perspective we must acknowledge the courage of families that are open about suicide; more awareness, less stigmatisation, and better treatment will save lives. From a psychological perspective, we must ensure that doctors and other healthcare workers recognise depression when it affects themselves, and receive good care to enable them to better take care of others. The Greeks said 'Physician, heal thyself'; the Swahili phrase is 'Mganga hajigangi' (a healer cannot treat himself). From a sociopolitical perspective, we must do more to ensure more caring hospitals and universities, more parity for mental health services and research, less stigmatisation of mental disorders, and fewer barriers to seeking help.

The consequences of the loss of a hero like Bongani Mayosi should not be underestimated. Heroes exemplify for us lives of courage, compassion and commitment, and so help give us fortitude, energy and optimism. Heroes are not infallible, however - they make errors and mistakes, they experience fear and setbacks, and this vulnerability and suffering also deserves acknowledgment. When a hero is lost, we can best pay tribute to their heroism by remembering their courage, compassion and commitment, and doing our best to embody these in our own lives and in our own institutions.

\section{Dan J Stein}

Department of Psychiatry and MRC Unit on Risk and Resilience in Mental Disorders, Faculty of Health Sciences, University of Cape Town and Groote Schuur Hospital, Cape Town, South Africa

dan.stein@uct.ac.za

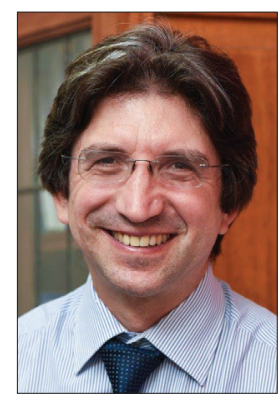

S Afr Med J 2018;108(9):701. DOI:10.7196/SAMJ.2018.v10819.13599 